\title{
Simulation Study on Mechanical Properties of Three-phase Asynchronous Motor Based on Mixed Programming
}

\author{
Tengfei Ma ${ }^{\mathrm{a}}$, Yanxiang $\mathrm{Wu}^{\mathrm{b}}$, You $\mathrm{Lv}^{\mathrm{c}}$ \\ College of Engineering Science \& Technology, Shanghai Ocean University, Shanghai, 201306, China

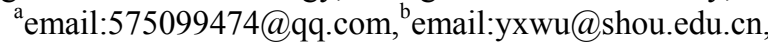 \\ cemail: 275392215@qq.com
}

\begin{abstract}
Studies on mechanical properties of three-phase asynchronous motor, we usually use Matlab to establish a model to achieve the simulation of the motor mechanical properties. In the process of the actual use, modify large number of parameters will cause many program errors and affect the experimental velocity. By the mixed programming of MATLAB and VB, we can use the feature of visualization interface of $\mathrm{VB}$ and the feature of software toolboxes and the function of drawing of Matlab. Combining Characteristics of $\mathrm{VB}$ and Matlab and using mixed programming of $\mathrm{VB}$ and Matlab to achieve simulation are useful attempts.
\end{abstract}

Keywords-three-phase asynchronous motor; mechanical properties; visual basic; matlab program.

\section{INTRODUCTION}

Recent years, DC motors have been replaced by asynchronous motors gradually, asynchronous motors are becoming the most important power device in electric drive field[1]. Against The problems that Matlab computing speed is slow in research and analysis applications in the mechanical properties of the motor. This method of mixed programming improved running speed. In this paper, through the analysis of mechanical properties of three-phase asynchronous motor, focuses on adopting COM(Component Object Model) generator to combine Matlab and VB to study the mechanical properties of three-phase asynchronous motor, which is proved to be more convenient and efficient.

\section{MECHANICAL PROPERTIES OF THREE-PHASE ASYNCHRONOUS MOTOR}

Under the condition of rated frequency and rated supply voltage, the relationship between electromagnetic torque and speed of three-phase asynchronous motor is called mechanical properties[1]. Artificial mechanical properties refers to artificially change the stator voltage, magnetic pole logarithm, working frequency to obtain the mechanical properties[4]. The relationship between electromagnetic torque and slip of three-phase asynchronous motor is:

$$
T e=\frac{m_{1} p U_{1}^{2} \frac{R 2^{\prime}}{S}}{2 \pi f_{1}\left[\left(R_{1}+\frac{R_{2}^{\prime}}{S}\right)+\left(X_{1 \sigma+} X_{2 \sigma^{\prime}}\right)^{2}\right]}
$$

In the above formula: $m_{1}$ and $f_{1}$ is on behalf of the number of phase and frequency of the power supply respectively; $\mathrm{P}$ is the magnetic poles number; $\mathrm{U}_{1}$ is the phase voltage of stator winding;
$S$ is the slip ratio; $R_{1}$ is the resistance of stator winding; $X_{1 \sigma}$ is the leakage reactance of stator winding; $\mathrm{R}_{2}$ ' is the converted resistance of stator winding; $\mathrm{X}_{2 \sigma}{ }^{\prime}$ is the converted leakage reactance of stator winding.

\section{IMPLEMENTATION METHOD OF MIXED PROGRAMMING OF MATLAB AND VB}

There are several methods to realize the mixed programming of Matlab and VB, this paper focuses on the activex components based on COM。

Introduction to COM: as an open component, $\mathrm{COM}$ has a very strong capacity of expansion [2]. Using ActiveX automation interface in the VB, Matlab can be called by VB as an ActiveX component. Type in "mbuild-setup" in Matlab, select the compiler of Matlab and the other compiler in the machine. After configuration is completed, Matlab can be connected to $\mathrm{C}++[3]$.

Use Matlab to create COM component. The exact process is as follows. First, use Matlab to create a M program. Second, type in "comtool" instruction to call out the main window of Matlab COM Build, which is necessarily needed for creating a COM component; select the file option, type in the name of new component and the class name, add the M program to the new project; click "build" button, after the compilation is done, the $\mathrm{M}$ program is converted to COM component. Third, use VB to call-out the DLL program in the COM component created by Matlab.

\section{THE EXAMPLE OF MIXED PROGRAMMING OF MATLAB AND VB}

\section{A. Create the M program}

The following $\mathrm{M}$ program is required for this paper. Function $[\mathrm{s}, \mathrm{Tmech}]=\mathrm{s}-\mathrm{T}$ (Un, Nphase, $\mathrm{P}, \mathrm{fN}, \mathrm{R} 1, \mathrm{Xl}, \mathrm{X} 2, \mathrm{Xm})$ omegas $=2 * \mathrm{pi}^{*} \mathrm{fN} / \mathrm{P}$; $\mathrm{nS}=60 * \mathrm{fN} / \mathrm{P}$

for $m=1: 5$

if $\mathrm{m}==1$

$\mathrm{R} 2=0.1$;

else if $m==2$

$\mathrm{R} 2=0.2$;

else if $\mathrm{m}==3$

$\mathrm{R} 2=0.5$;

else if $\mathrm{m}==4$

$\mathrm{R} 2=1.0$;

else

$\mathrm{R} 2=1.5$;

end

for $n=1: 2000$

$\mathrm{s}(\mathrm{n})=\mathrm{n} / 2000$; 
Tmech $=$ Nphase $* \mathrm{P} * \mathrm{U} 1 * 2 * \mathrm{R} 2 / \mathrm{s}(\mathrm{n}) /$ omegas $/\left[(\mathrm{R} 1+\mathrm{R} 2 / \mathrm{s}(\mathrm{n}))^{\wedge} 2+(\right.$ $\left.\mathrm{X} 1+\mathrm{X} 2)^{\wedge} 2\right]$

plot (s(n),Tmech)

end

if $m==1$

hold

end

end

hold

xlabel('Slip Ratio')

ylabel('Electromagnetic Torque ')

title('Mechanical characteristic for asynchronous motor with different rotor resistances')

disp('End')

\section{B. Create the VB program}

The window of $\mathrm{VB}$ and the control property table are shown as follows:

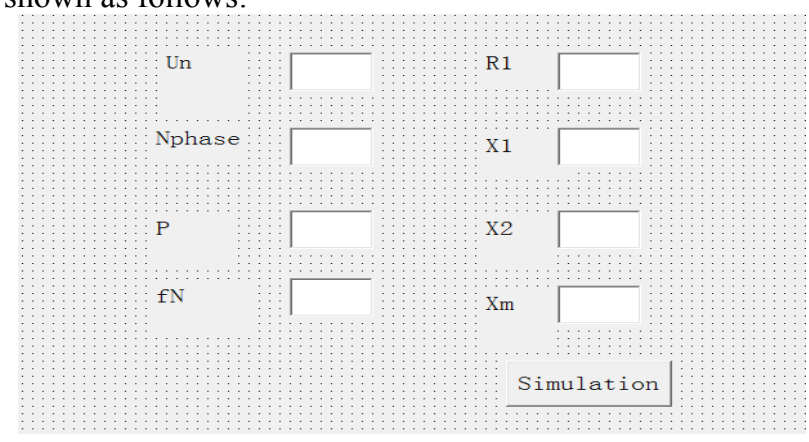

Figure 1. The window of VB

TABLE I. CONTROL PROPERTY TABLE

\begin{tabular}{|c|c|c|c|}
\hline $\begin{array}{c}\text { The } \\
\text { control } \\
\text { type and } \\
\text { name }\end{array}$ & $\begin{array}{l}\text { the } \\
\text { corresponding } \\
\text { input }\end{array}$ & $\begin{array}{c}\text { The control } \\
\text { type and } \\
\text { name }\end{array}$ & Control property \\
\hline Text1 & Text="Un" & Label1 & Caption="Un" \\
\hline Text2 & $. T e x t=" N p h a s e "$ & Label2 & .Caption="Nphase" \\
\hline Text3 &. Text="P" & Label3 & .Caption="P" \\
\hline Text4 & Text="fN" & Label4 & Caption="Fn" \\
\hline Text5 & $. T e x t=" R_{1} "$ & Label5 & .Caption $=" \mathrm{R}_{1}$ " \\
\hline Text6 & $. T e x t=" X_{1} "$ & Label6 & Caption $=" X_{1} "$ \\
\hline Text7 & $. T e x t=" X_{2} "$ & Label7 & .Caption=" $\mathrm{X}_{2} "$ \\
\hline \multirow[t]{2}{*}{ Text8 } & Text $=" \mathrm{X}_{\mathrm{m}} "$ & Label8 & Caption="Xm" \\
\hline & & $\begin{array}{c}\text { Command } \\
\text { button }\end{array}$ & .Caption="Simulation" \\
\hline
\end{tabular}

\section{Simulation result}

Type in the parameters, the result is shown as follow:

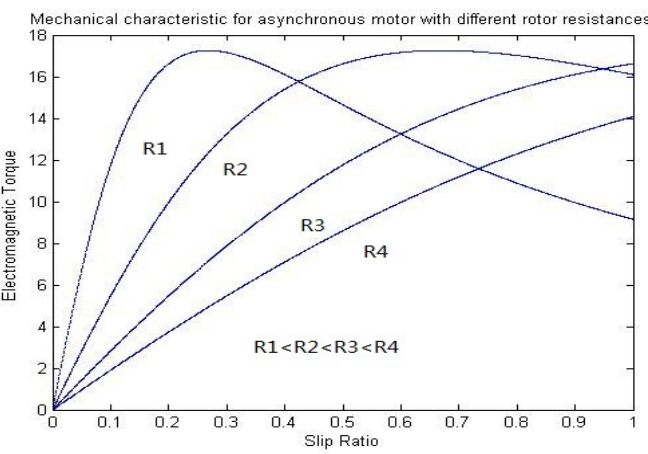

Figure 2.The result of mixed programming

\section{Modify the parameters}

TABLE II.CHANGE THE SUPPLY VOLTAGE

\begin{tabular}{|c|c|c|c|c|c|c|c|}
\hline $\mathrm{U}_{\mathrm{n}}$ & Nphase & $\mathrm{P}$ & $\mathrm{fN}$ & $\mathrm{R} 1$ & $\mathrm{X} 1$ & $\mathrm{X} 2$ & $\mathrm{X}_{\mathrm{m}}$ \\
\hline 220 & 3 & 2 & 50 & 0.095 & 0.680 & 0.672 & 18.7 \\
\hline
\end{tabular}

The result of changing supply voltage is shown as follow:

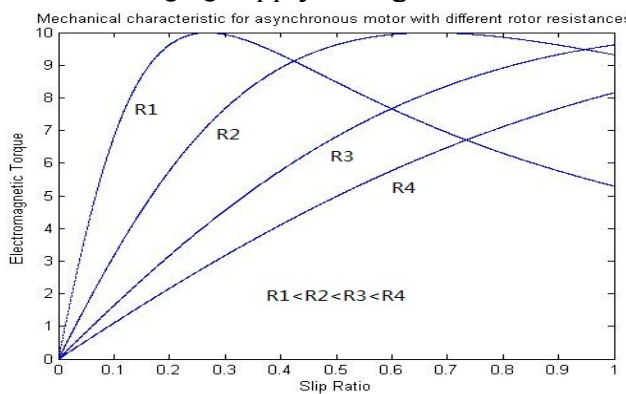

Figure 3.The result of changing supply voltage

\section{V.CONCLUSION}

Using the mixed programming is more efficient and accurate. By the mixed programming of MATLAB and VB, we can combine the advantages of Matlab and VB, accelerate the speed of simulation. Modify the parameters on the concise interface of VB, which can avoid mistakes and save time. It is proved that using mixed programming is more convenient and more quick.

\section{REFERENCES}

[1] Gu Sheng-Gu, Electric Machine and Drag. Beijing: Machinery Industry Press, 2007.

[2] Zhang Hai-Shen, Dong Ai-Qin, Wang Zhi-Jie, Simulation research on mechanical properties of three-phase asynchronous motor based on COM hybrid programming. Journal of Electric Power, 26(6), pp.499-501, November 2011.

[3] Zhu Zhi-Song, Guo Xiao-Li, Zhu Xiao-Song. Discussion of mixed programming of Matlab and VB. Electronic Technical Application, 6 (9), pp.18-19,2003.

[4] Liu Jin-Bo, Zhang Cheng-Hui, Electric Machine and Drag. Beijing: Tsinghua University Press, 2006. 